\title{
Author Index Volume 22 (2013)
}

The issue number is given in front of the pagination

\author{
Abdelhafez, T.H., see Tabll, A. $(3,4)$ 55-65 \\ Abdolalizadeh, J. (1,2) 1-8 \\ Abdolalizadeh, J., see Maleki, L.A. (3,4) 67-71 \\ Aghebati-Maleki, L., see Shahneh, F.Z. (1,2) 15-19 \\ Akbari, A.M. (1,2) 1-8 \\ Babkin, I.V., see Tyumentseva, M.A. (1,2) 31-49 \\ Baradaran, B. (1,2) 1-8 \\ Baradaran, B., see Maleki, L.A. (1,2) 9-13 \\ Baradaran, B., see Maleki, L.A. (3,4) 67-71 \\ Baradaran, B., see Shahneh, F.Z. (1,2) 15-19 \\ Barton, E., see Roye-Green, K. (3,4) 87-93
}

Christensen, C.J., see Wagner, L.A. (1,2) 21-29

Dawson, J., see Roye-Green, K. (3,4) 87-93

Dunn, D.M., see Wagner, L.A. (1,2) 21-29

El Abd, Y., see Tabll, A. (3,4) 55-65

El Awady, M., see Tabll, A. $(3,4)$ 55-65

El Din, N.G.B., see Tabll, A. $(3,4)$ 55-65

El Shenawy, R., see Tabll, A. $(3,4)$ 55-65

El-Mohamady, H., see Tabll, A. $(3,4)$ 55-65

Gleich, G.J., see Wagner, L.A. (1,2) 21-29

Lebedev, L.R., see Tyumentseva, M.A. (1,2) 31-49

Majidi, J., see Maleki, L.A. (1,2) 1-8

Majidi, J., see Maleki, L.A. (1,2) 9-13

Majidi, J., see Maleki, L.A. (3,4) 67-71

Maleki, L.A., B. Baradaran, J. Majidi, M. Mohammadian and F.Z. Shahneh, Future prospects of monoclonal antibodies as magic bullets in Immunotherapy $(1,2) 9-13$

Maleki, L.A., D. Shanehbandi, J. Majidi, M. Yusefi, J. Abdolalizadeh, M. Orangi and B. Baradaran, Production of Anti-CD14 monoclonal antibody using synthetic peptide of human CD14 as immunizing antigen $(3,4) 67-71$
Maleki, L.A., J. Majidi, B. Baradaran, J. Abdolalizadeh and A.M. Akbari, Production and characterization of murine monoclonal antibody against synthetic peptide of CD34 $(1,2) 1-8$

Mc Morris, N., see Roye-Green, K. (3,4) 87-93

Mohammadian, M., see Maleki, L.A. (1,2) 9-13

Morozova, V.V., see Tyumentseva, M.A. $(1,2)$ 31-49

Naganawa, Y., M. Takeda, M. Shimmoto and H. Shinmoto, Epitope analysis of Japanese cedar pollen allergen Cry $\mathrm{j} 1$ with the human monoclonal antibody 4701-1 $(3,4) 73-76$

Orangi, M., see Maleki, L.A. (3,4) 67-71

Perkins, S., see Wagner, L.A. (1,2) 21-29

Redd, M.J., see Wagner, L.A. (1,2) 21-29

Roye-Green, K., R. Willis, N. Mc Morris, J. Dawson, D. Whittle, E. Barton and M. Smikle, Autoimmune hepatitis in a Jamaican cohort spanning 40 years $(3,4) 87-93$

Shahneh, F.Z., B. Baradaran, F. Zamani and L. Aghebati-Maleki, Tumor angiogenesis and antiangiogenic therapies $(1,2)$ 15-19

Shahneh, F.Z., Current challenges in metastasis: Disseminated and circulating tumor cells detection $(3,4) 77-85$

Shahneh, F.Z., see Maleki, L.A. (1,2) 9-13

Shahneh, F.Z., Sensitive antibody-based CTCs detection from peripheral blood $(1,2)$ 51-54

Shanehbandi, D., see Maleki, L.A. $(3,4) 67-71$

Shimmoto, M., see Naganawa, Y. $(3,4) 73-76$

Shinmoto, H., see Naganawa, Y. $(3,4) 73-76$

Smikle, M., see Roye-Green, K. $(3,4)$ 87-93

Spangrude, G.J., see Wagner, L.A. (1,2) 21-29 
Tabll, A., Y. El Abd, N.G.B. El Din, R. El Shenawy, T.H. Abdelhafez, M. El Awady, H. El-Mohamady and S. Viazov, Establishment of human clones producing neutralizing human monoclonal antibodies to the envelope E1/E2 protein of hepatitis C virus by EBV immortalization of immune $\mathrm{CD} 22^{+}$ B cells $(3,4)$ 55-65

Takeda, M., see Naganawa, Y. $(3,4) 73-76$

Tikunova, N.V., see Tyumentseva, M.A. (1,2) 31-49

Tyumentseva, M.A., V.V. Morozova, L.R. Lebedev, I.V. Babkin and N.V. Tikunova, Presence of aberrant $\mathrm{V}_{\mathrm{H}} 6$ domains in anti-interferon- $\gamma$ autoantibodies in multiple sclerosis $(1,2)$ 31-49

Viazov, S., see Tabll, A. $(3,4)$ 55-65
Wagner, L.A., S. Wang, E.A. Wayner, C.J. Christensen, S. Perkins, G.W. Ward, R.B. Weiss, D.M. Dunn, M.J. Redd, G.J. Spangrude and G.J. Gleich, Developing and mature human granulocytes express ELP 6 in the cytoplasm $(1,2)$ 21-29

Wang, S., see Wagner, L.A. (1,2) 21-29

Ward, G.W., see Wagner, L.A. (1,2) 21-29

Wayner, E.A., see Wagner, L.A. (1,2) 21-29

Weiss, R.B., see Wagner, L.A. (1,2) 21-29

Whittle, D., see Roye-Green, K. $(3,4)$ 87-93

Willis, R., see Roye-Green, K. (3,4) 87-93

Yusefi, M., see Maleki, L.A. (3,4) 67-71

Zamani, F., see Shahneh, F.Z. (1,2) 15-19 